Int. J. Dev. Biol. 56: 755-760 (2012)

doi: $10.1387 / \mathrm{ijdb} .120080 \mathrm{fn}$

\title{
The secondary human yolk sac has an immunophenotype indicative of both hepatic and intestinal differentiation
}

\author{
FRANCISCO F. NOGALES* and ISABEL DULCEY \\ Department of Pathology, San Cecilio University Hospital, Granada, Spain
}

\begin{abstract}
Although the microscopy of the secondary human yolk sac (SHYS) is well known, few studies have addressed its immunohistochemical profile. The SHYS is involved in the synthesis, absorption and transfer of various proteins and behaves as a temporary liver and intestine. The objective of this study was to evaluate the presence of immunohistochemical markers of hepatic and intestinal function in the SHYS. We performed a retrospective histological and immunohistochemical study of 26 SHYS from spontaneous abortions and tubal pregnancies, 15 of which were from the $7^{\text {th }}$ to $8^{\text {th }}$ week. The antibodies used were against $\alpha$-foetoprotein (AFP), glypican 3 (GLP3), hepatocyte-paraffin-1 (HepPar-1), villin, CDX2, SALL4 and podoplanin (D2-40). Early SHYS from the $5^{\text {th }}$ to the $8^{\text {th }}$ week revealed a network of intracellular vesicles communicating with the lumen of endodermal tubules that were highlighted by intense membrane AFP expression. Endodermal cells consistently expressed AFP, GLP3, SALL4, hep-par-1, villin and CDX2, while mesothelial cells only expressed D2-40. The endodermal layer of the SHYS from the $5^{\text {th }}$ to the $8^{\text {th }}$ week revealed a transient canalicular network which was highlighted by strong membranous AFP expression; this may represent the substrate of a SHYS transport system during its period of maximal activity. The synthetic and transfer functions of the yolk sac endoderm were reflected in a hybrid immunophenotype in which proteins characteristic of hepatic function such as AFP, GLP3, SALL4 and hep-par-1 were coexpressed simultaneously with others such as villin and CDX2, indicative of an intestinal role.
\end{abstract}

KEY WORDS: secondary human yolk sac, hepatic function, intestinal differentiation marker, AFP, HepPar-1

The secondary human yolk sac (SHYS) is an organ which plays a crucial role in early development. Although it has not attracted the attention it deserves in the literature, its optic microscopy and ultrastructure are well known (Hesseldahl et al., 1969; Jones et al., 1995a; Nogales-Fernandez et al., 1977; Pereda et al., 1999; Takashina et al., 1993). Its clinical relevance in relationship with early pregnancy loss has been studied both ultrasonographically (Ferrazzi et al., 1988; Hustin et al., 1987; Jauniaux et al., 2005; Jauniaux et al., 1991; Kucuk etal., 1999) and histologically (Nogales et al., 1992; Nogales et al., 1993; Nogales et al., 1995).

This essential structure is vital for protein synthesis, as can be seen from its production of a wide range of substances (Gitlin et al., 1969; Gitlin et al., 1970; Gitlin et al., 1972; Jones et al., 1995b; Shi et al., 1985), especially those contributing to blood formation (Gitlin et al., 1969; Gulbis et al., 1994). Furthermore, the types of proteins it synthesizes are evidence that, for a short period of time, the SHYS is involved in absorptive and transfer roles, thus behaving as a temporary liver and intestine (Gulbis et al., 1998; Gulbis et al., 1994; Gulbis et al., 1992; Shi et al., 1985). Indeed, it is the principal route of entry of many proteins and iron to the embryo. However, in the last decade, little information about the immunohistochemistry of the SHYS has been provided, with only few studies dealing with the shared immunohistochemical expression of some proteins (Preda et al., 2011) by the SHYS and human yolk sac tumours in order to prove the vitelline identity of these neoplasms (Nogales et al., 2012; Preda et al., 2011).

The present work reports, for the first time, the demonstration and location in the SHYS of highly characteristic immunohistochemical markers that are associated with hepatic (glypican 3 and hepatocyte-paraffin-1) and intestinal (villin and CDX2) functions, thus providing a morphological basis for its temporary physiological role as an active interface between the exocoelomic cavity and the developing embryo. Additionally, SALL4, a pluripotency marker and podoplanin, a mesothelial marker, were also analyzed.

This hypothesis is supported further by the expression, distribution and location of transport proteins such as $\alpha$-foetoprotein

Abbreviations used in this paper: AFP, alpha-foetoprotein; GLP, glypican; H\&E, Hematoxylin and eosin stain; HepPar, hepatocyte-paraffin; SHYS, secondary human yolk sac.

\footnotetext{
*Address correspondence to: Francisco F. Nogales. Department of Pathology. San Cecilio University Hospital, 18012 Granada, Spain. e-mail: fnogales@ ugr.es
} 
(AFP) in a network of intracellular channels connected with the endodermal tubules that may represent the substrate of a transfer system between embryo and the exocoelomic cavity.

\section{Results}

\section{Hematoxylin and eosin stain (H\&E)}

The SHYS histology was assessed according to its developmental stage: the only available early sac from the 5- $6^{\text {th }}$ week showed a trilaminar wall structure with an inner linear endoderm and an external mesothelial layer with haemopoietic islands present in its intervening mesenchymal layer. The endodermal cells had rounded large nuclei with macronucleoli and an eosinophilic, granular cytoplasm populated by numerous intracytoplasmic vesicles. Frequent mitoses were present.

In sacs from the $7-8^{\text {th }}$ week, the thickness of the endodermallayer was substantially increased and proliferated to form downwards columns of cells that eventually became hollow, empty tubules (Fig. 1A). Their cytoplasm exhibited abundant intracellular lumina (Fig. 1B) often in close apposition with the endodermal tubules and the haemopoietic islands present in the mesenchyme. Some anisokaryosis was often present (Fig. 1B). The mesothelium was unremarkable.

Involuting sacs from the $9-12^{\text {th }}$ week revealed a flattened or coarsely vacuolated endoderm with collapse and flattening of the endodermal tubules and disappearance of the intracellular vesicles. Blood islands progressively disappeared while the mesothelial layer became prominent and vacuolated. At the end of this period, endodermal cells had become atrophic and been desquamated into the endodermal cavity as amorphous eosinophilic granular
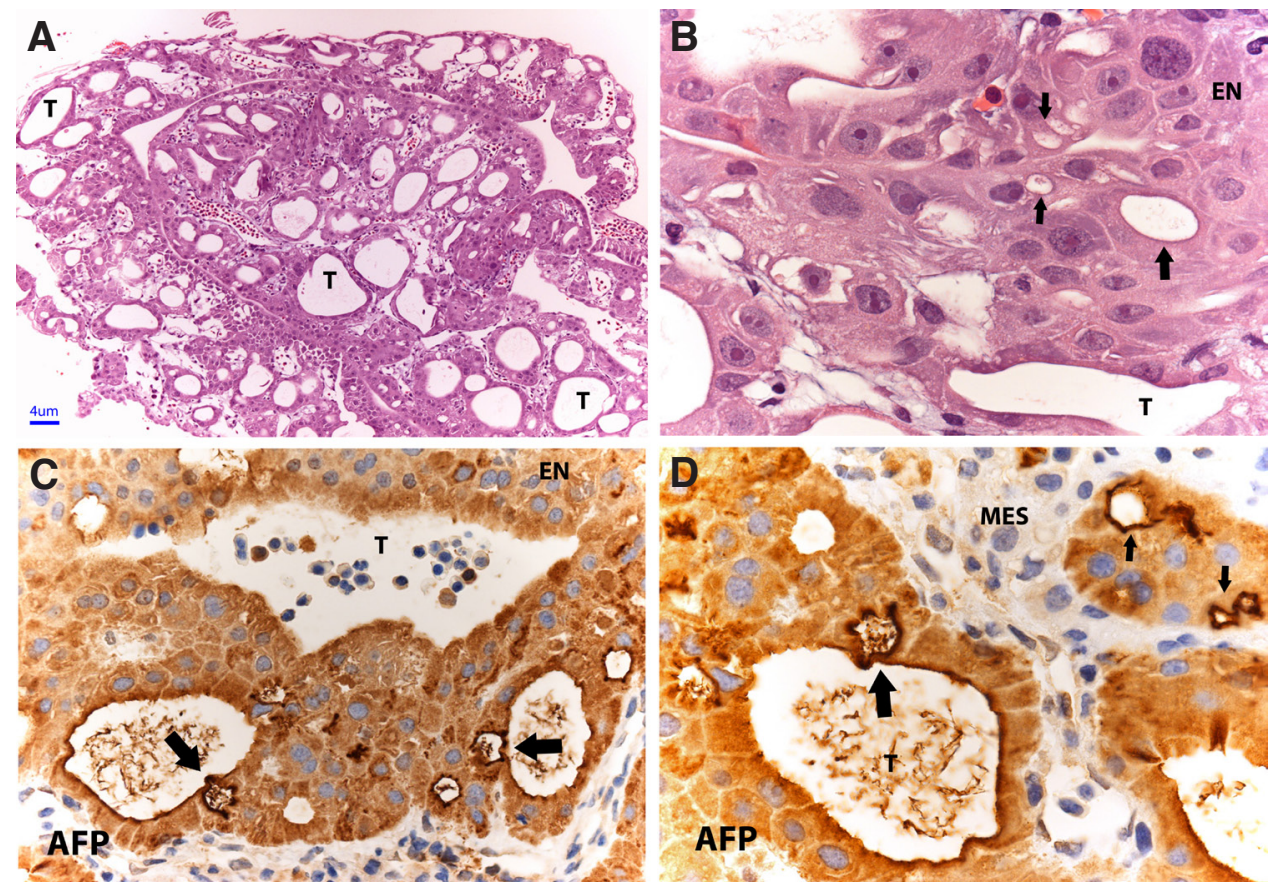

Fig. 1. A partly collapsed secondary human yolk sac from the $8^{\text {th }}$ week. (A) Note the numerous endodermal tubules(T). (B) Higher magnification of the endodermal epithelium (EN). Cells have large, irregular nuclei with prominent nucleoli. (C,D) Their ample cytoplasm reveals lumina (arrows) whose membranes are intensely AFP immunoreactive (arrows). (D) AFP immunoreactivity is absent in the mesenchyme (MES). (C,D) Intracellular lumina communicate with the large endodermal tubules; see arrows in (C,D).
TABLE 1

\section{ANTIBODIES USED IN THIS STUDY}

\begin{tabular}{llll} 
Antibody & Clone & Dilution & Vendor \\
\hline Glypican 3 (GLP3) & SP86 & Prediluted & MasterDiagnostica, Spain \\
$\alpha$-foetoprotein (AFP) & Polyclonal & Prediluted & DAKO, Denmark \\
Hepatocyte paraffin 1 (HepPar-1) & OCH1E5 & Prediluted & DAKO, Denmark \\
CDX2 & DAK-CDX2 & Prediluted & DAKO, Denmark \\
Villin & 1D2 C3 & Prediluted & DAKO, Denmark \\
Podoplanin (D2-40) & D2-40 & Prediluted & DAKO, Denmark \\
Calretinin & DAK-Calret 1 & Prediluted & DAKO, Denmark \\
Anti-Mesothelioma antibody & HBME-1 & Prediluted & DAKO, Denmark \\
\hline
\end{tabular}

debris. Parietal fibrosis and calcification were present.

\section{Immunohistochemistry}

$\alpha$-foetoprotein (AFP) secretion was seen as early as the $5^{\text {th }}$ week and remained positive throughout the evolution of the SHYS, even in the atrophic or shed endodermal cells of the involuting sacs of 10-11 weeks. Strong cytoplasmic stain was exclusively found in the endodermal layer. It is worth noting that in SHYS from 5-8 weeks, the numerous intracellular vesicles were highlighted by a strong membrane AFP expression (Figs. 1 C,D). Vesicles were seen to communicate with the endodermal tubules, which also expressed a strong luminal stain (Fig. 1D). Some hematopoietic cells were also AFP positive (Fig. 1C). Mesothelial layer cells were negative, although some diffusion and background stain occurred. In the accompanying embryonal tissues, a strong expression was identified in both the liver trabeculae and some blood cells.

Glypican 3 (GLP3) staining pattern was similar in strength and location to that of AFP, albeit with a minimal background stain, remaining positive throughout the evolution of endoderm. Although the endodermal cytoplasm was well stained, it had a stronger membranous intensity than AFP (Fig. 2A). The endodermal intracellular vesicles and tubules also showed a prominent apical and luminal stain. In the available embryonal tissues, liver cells showed a constantly strong positivity. This antibody was also expressed in developing mesenchymal cells and the neuroepithelial structures of embryos.

Hepatocyte Paraffin-1 (HepPar-1) expression was reduced to cells of the endodermal layer and was also constantly present throughout the evolution of the SHYS. It had a characteristically strong, coarsely granular cytoplasmic (mitochondrial-type) staining pattern (Fig. 2B). Even atrophied or shed endodermal cells of the involutive period also showed similar reactivity. Among the embryonal tissues, only liver was specifically stained with a similar expression.

Villin showed a strong cytoplasmic and membranous expression in the endoderm throughout the evolution of the 
TABLE 2

\section{SHYS IMMUNOPHENOTYPE}

\begin{tabular}{ccccccccc} 
& & \multicolumn{7}{c}{ ANTIBODIES } \\
\cline { 2 - 9 } Week & $\#$ & AFP & GLP3 & HepPar-1 & Villin & CDX2 & SALL4 & D2-40 \\
\hline $5-6$ & 1 & $1 / 1$ & - & - & - & - & - & - \\
$7-8$ & 15 & $15 / 15$ & $15 / 15$ & $12 / 14^{*}$ & $11 / 12^{*}$ & $10 / 14^{\star}$ & $10 / 13^{*}$ & $15 / 15$ \\
$9-11$ & 10 & $10 / 10$ & $10 / 10$ & $9 / 10$ & $5 / 9^{*}$ & $9 / 10$ & $3 / 8^{*}$ & $8 / 9^{*}$ \\
\hline
\end{tabular}

All antibodies, except for podoplanin D2-40, were expressed in the endodermal layer. Only podoplanin was positive in the mesothelium.

${ }^{*}$ ) In some cases, step sections failed to produce a sufficient number of slides to complete the study of some antibodies

TABLE 3

\section{IMMUNOHISTOCHEMICAL EXPRESSION OF CONCOMITANT EMBRYONAL TISSUES}

\begin{tabular}{|c|c|c|c|c|c|c|c|}
\hline \multirow[b]{2}{*}{ Weeks } & \multicolumn{7}{|c|}{ ANTIBODIES } \\
\hline & $\#$ & AFP & GLP3 & HepPar-1 & Villin & CDX2 & SALL4 \\
\hline \multirow[t]{3}{*}{$7-8$} & \multirow[t]{3}{*}{6} & \multirow[t]{3}{*}{ L 6/6 } & \multirow{3}{*}{$\begin{array}{c}\text { L 6/6 } \\
\text { Mes 6/6 } \\
\text { Neu 6/6 }\end{array}$} & \multirow[t]{3}{*}{ L $6 / 6$} & L 6/6 & \multirow{3}{*}{ Gut 2/6 } & * \\
\hline & & & & & & & L $1 / 4$ \\
\hline & & & & & Gut 3/3 & & Neu $6 / 6$ \\
\hline \multirow[t]{3}{*}{$9-11$} & \multirow[t]{3}{*}{4} & \multirow[t]{3}{*}{ L $4 / 4$} & L $4 / 4$ & \multirow[t]{3}{*}{ L 4/4 } & L $4 / 4$ & \multirow[t]{3}{*}{-} & \multirow[t]{3}{*}{ Neu $4 / 4$} \\
\hline & & & Mes 4/4 & & & & \\
\hline & & & $\mathrm{Neu} 4 / 4$ & & & & \\
\hline
\end{tabular}

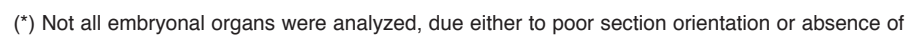
material in successive slides. KEY: L, liver; Mes, mesenchyme; Neu, neuroepithelium.
SHYS and embryos are shown in Tables 2 and 3. As a summary, Fig. 3 A-E shows the comparative expression of the antibodies in a $7^{\text {th }}$ week SHYS.

\section{Discussion}

Clinical interest in SHYS morphology has been focused mainly on its ultrasound appearance during the first trimester. Although it has been proposed that SHYS changes may act as markers for some chromosomal abnormalities (Schmidt et al., 2011), it seems that the predictive value of SHYS measurements in determining the outcome of an early pregnancy is limited, as the alterations in SHYS size are the consequence of poor embryonic development or embryonic death rather than being the primary cause of early pregnancy failure (Jauniaux et al., 2005). This clinical perception agrees with morphological studies of the SHYS in spontaneous pregnancy loss, which revealed only non-specific, degenerative features related to embryonal death and retention (Nogales et al., 1992; Nogales et al., 1993; Nogales et al., 1995).

In the present paper, we analyze SHYS material originating from spontaneous pregnancy loss. Sacs from all evolutive periods were included and there were only minimal degenerative changes. Due to the limits imposed by such scanty material, we focused on the demonstration of a short series of readily available antibodies characteristic of the presumed secretory, synthetic and absorptive endodermal layer (Fig. 2C). In the embryonal tissues it was markedly positive in the cytoplasm of liver cells and in the apical membranes and cytoplasm of the intestinal lining.

$C D X 2$ was strong and diffusely expressed in the nuclei of early and sacs from the $7^{\text {th }}$ to $8^{\text {th }}$ week, becoming weaker and more focal in distribution during the involution period (Fig. 2D). In embryos showing gut structures, lining cells had a strong nuclear positivity which was, however, absent in liver and other tissues.

SALL4broadly expressed a similar nuclear staining pattern to CDX2 in both chronology and intensity (Fig. 2E). In the embryonal tissues it was strongly expressed in neuroepithelium.

Podoplanin (D2-40) expression was reduced to the mesothelial layer (Fig. 2F), which failed to stain for other markers. In the 3 instances where sections were still available, mesothelium was negative for other characteristic mesothelial antibodies such as calretinin and HBME-1.

The immunohistochemical findings of both

Fig. 2. Immunophenotype of another secondary human yolk sac from the $8^{\text {th }}$ week, during which haematopoiesis ( ${ }^{*}$ ) is prominent. (A) GLP3 delineates endodermal membranes. (B) Granular cytoplasmic (mitochondrial) positivity for HepPar1 is prominent. (C) Villin shows strong membrane and cytoplasm expression, while CDX2 (D) and SALL4 (E) reveal nuclear positivity. (F) D240 podoplanin is only expressed in mesothelial cells.
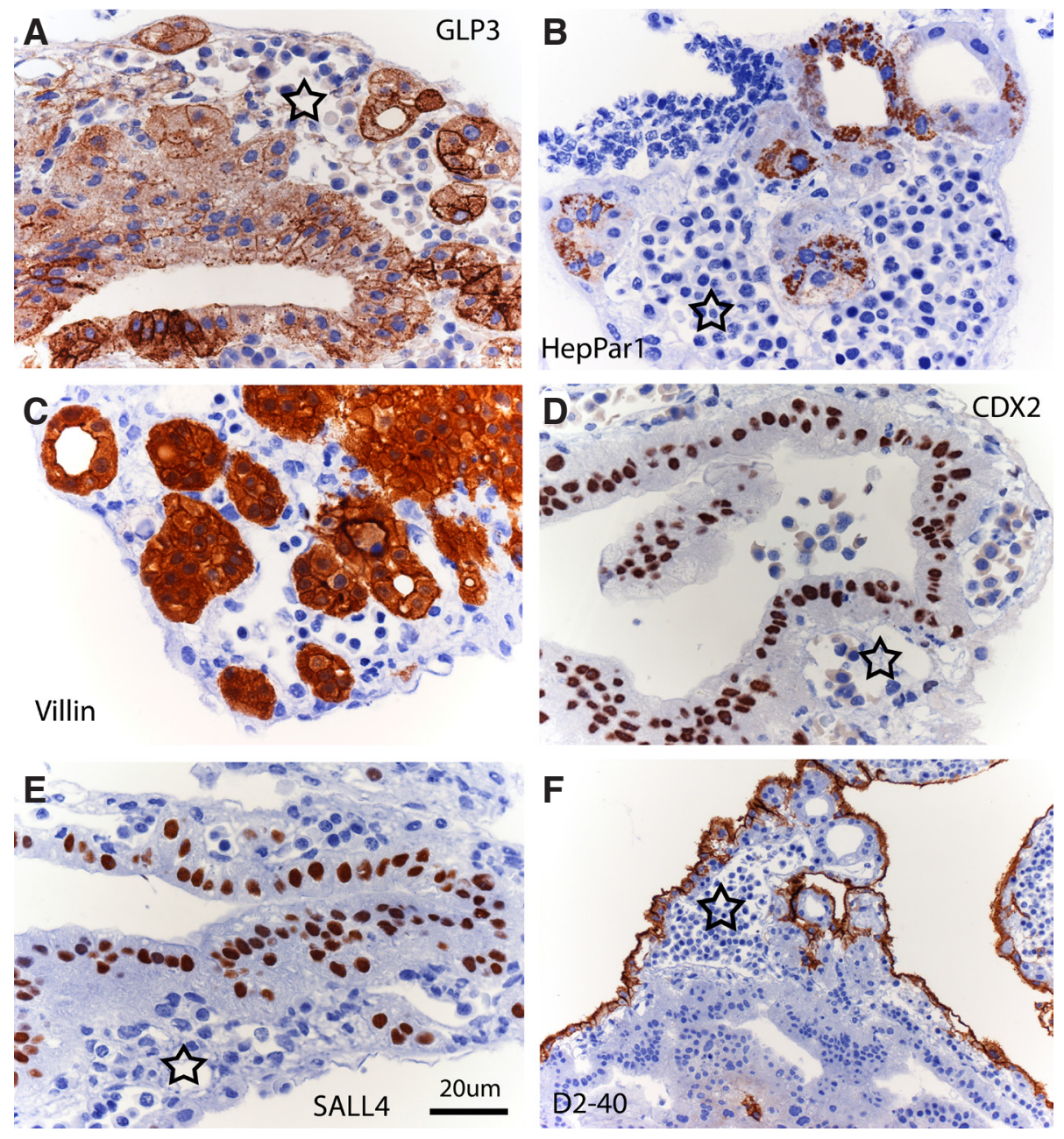
functions of the SHYS as a temporary liver and intestine and also used in the diagnosis of yolk sac tumours (Nogales et al., 2012).

SHYS has been considered a transfer organ between the embryo and the exocoelomic cavity (Gulbis et al., 1998), implying a role of active synthesis, absorption and transference of proteins during a short but crucial period of ontogenesis.

Optic microscopy shows the endoderm lining the yolk sac cavity to have a progressively complex structure, developing short columns of cells that contain an abundant network of intracellular vesicles. These structures are present in the earliest SHYS of this study at the $5^{\text {th }}$ week, but they eventually collapse and disappear in involutive sacs. Indeed, they seem to be present only during its period of maximum activity.

Ultrastructurally, SHYS endodermal cells share many common
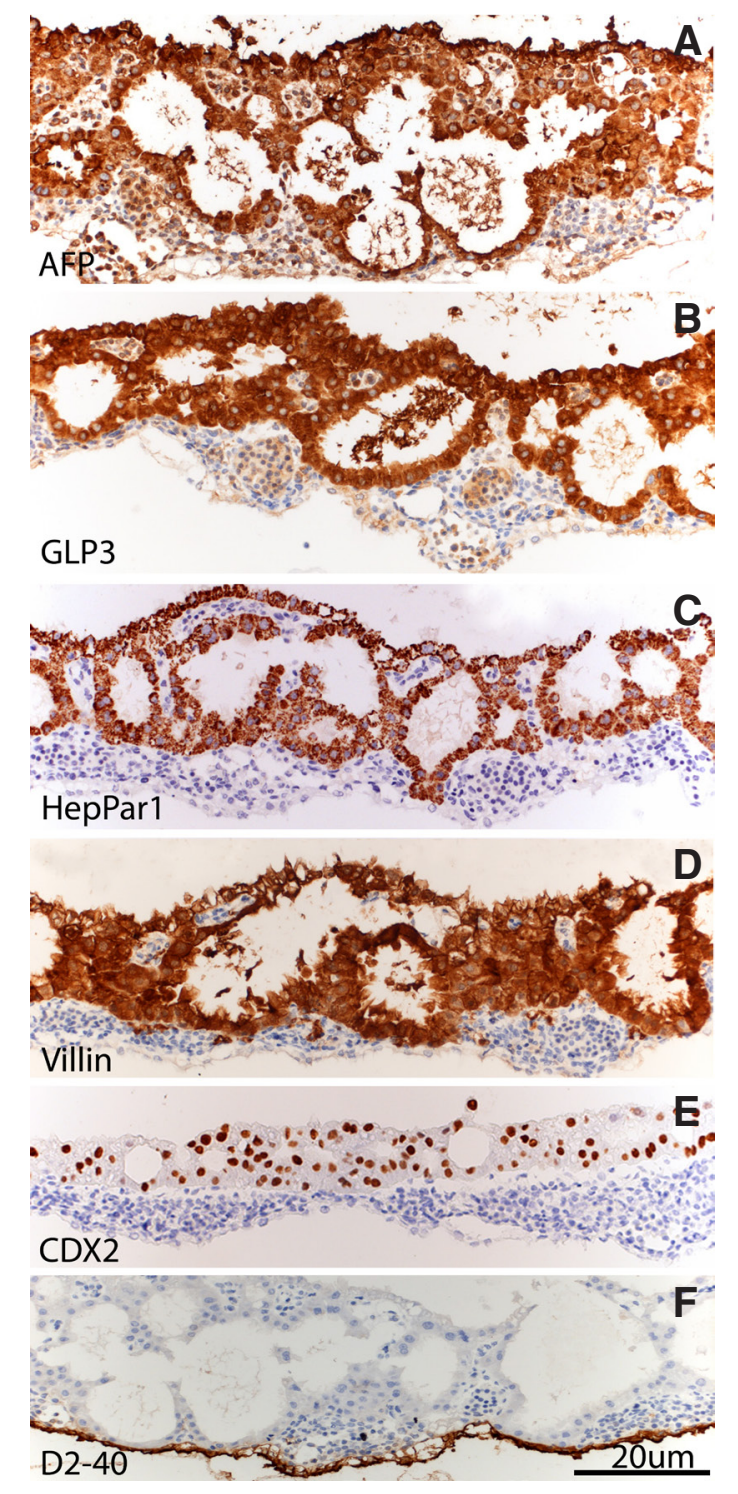

Fig. 3. Immunophenotype of a secondary human yolk sac from the $7^{\text {th }}$ week. The endoderm is strongly positive in both cytoplasm and membrane for (A) AFP and (B) GLP3. (C) HepPar1 exhibited a coarse granular expression. (D) Villin immunoreactivity is intense in the cytoplasm and membrane. (E) CDX2 labeling is intense in the nucleus. (F) Only the mesothelial layer presented podoplanin immunoreactivity. features with hepatic ones, having a glycogen-rich cytoplasm, well-developed Golgi complex, and abundant rough endoplasmic reticulum profiles (Jones etal., 1995a; Pereda etal., 1999; Takashina et al., 1993). Well-developed apical microvilli are present on the tubular surface and also line the numerous intracellular vesicles (Takashina et al., 1993) that will eventually coalesce to form a complex system of endodermal tubules. They are likely to have a role in transport of various substances due to their close relationship with blood islands, mesenchymal capillaries and mesothelium.

In this paper we demonstrate that this transient canaliculotubular complex displays a strong apical membrane staining for both AFP and GLP3, possibly indicating an active transport of these important proteins.

The functional similarities of the SHYS endodermal cells with hepatic and intestinal ones lie in their shared synthesis of proteins such as AFP, prealbumin, albumin, caeruloplasmin, fibrinogen, plasminogen, lipoproteins, $\alpha 1$-protease inhibitor, transferrin, GLP3, etc. (Gitlin et al., 1969; Gitlin et al., 1970; Gitlin et al., 1972; Gulbis et al., 1998; Gulbis et al., 1992; Preda et al., 2011; Shi et al., 1985). Among these, AFP and GLP3 are only expressed by developing hepatocytes (Kandil et al., 2007; Mizejewski et al., 2001) and have a similar distribution in both SHYS and liver. AFP function resides in the binding and transport of various ligands and recently an additional role as a growth regulator has been recognized (Mizejewski et al., 2001). Glypican 3 also acts as a modulator, activating intracellular signaling proteins and growth factors (Filmus et al., 2008). Their similar location and staining patterns in SHYS would reflect a synergic relationship, possibly related to cell growth control.

HepPar-1 is an empirically obtained monoclonal antibody (Wennerberg et al., 1993) raised against formalin-fixed, paraffin embedded hepatic tissue that is highly specific of both adult and embryonal liver cells, both normal and neoplastic. Outside the liver, it is only focally present in the glands of the small intestine and shows a weak expression in gastric glands (Lugli et al., 2004). Recently, the antigen for this antibody has been shown to be carbamoyl phosphate synthetase 1, an enzyme in the urea cycle located in mitochondria (Butler et al., 2008). This hepatic antigen has not been previously studied in the SHYS. Here, it was consistently present throughout the development of the SHYS from the $7^{\text {th }}$ week onwards and was also exclusively expressed by the liver cells of the accompanying embryos.

Villin is a $\mathrm{Ca}^{2+}$ regulated actin-binding protein that is expressed early during embryogenesis, being present in the mouse yolk sac in early stage visceral endodermal cells (Maunoury et al., 1988). In the human embryo, it is found at the $8^{\text {th }}$ week in the early intestinal tube. It is considered an early marker of endodermal cell lineage and it is identified in gastrointestinal, renal and urogenital epithelial cells (Robine et al., 1985). Villin is regarded as an early marker of committed intestinal absorptive cells (Khurana et al., 2008), being expressed also by liver ducts. The expression of villin in the SHYS and embryonal liver cells is consistent with both an intestinal and hepatic phenotype for the SHYS, where it is present in both the free membrane surfaces delineating endodermal tubules and the intracellular vesicles. A diffuse cytoplasmic stain was also present in both the SHYS and embryonal liver cells.

CDX2, a caudal-like homeodomain-containing transcription factor, is expressed in intestinal endoderm posterior to the stomach throughout gestation and adult tissues, where its strong expres- 
sion is mostly found in the nuclei of small and large intestine and pancreatic ducts (Moskaluk et al., 2003). Metaplastic conditions that reproduce intestine are also CDX2 positive (Nicolae et al., 2011) as well as some unusual metaplasias such as morules in various organs (Houghton et al., 2008). Its early functions include promotion of trophoblast differentiation (Stringer et al., 2012) and determination of blastocyst polarity (Jedrusik et al., 2008). Later on, it is involved in the differentiation and development of the intestine, but is not expressed by liver, even at an early stage of differentiation, as confirmed in this study by its absence in the hepatic tissue of all our accompanying embryos. It is worth noting that its expression was strong and diffuse in sacs from the $7-8^{\text {th }}$ week but diminished to a weak and focal stain in the older involuting ones.

SALL4 is a transcriptional activator of Pou5f1 and has a critical role in the maintenance of cell pluripotency by modulating Oct4 expression (Zhang et al., 2006). In the liver, SALL4 plays a decisive role in controlling the lineage commitment of hepatoblasts not only by inhibiting their differentiation into hepatocytes but also driving their differentiation toward cholangiocytes (Oikawa et al., 2009). So, it would seem that SALL4 is crucial in liver cell differentiation and its strong expression in early SHYS could be related to its early hepatic function.

Bile secretion only takes place at the $12^{\text {th }}$ week (Crawford et al., 2002) and is not needed at this developmental stage; consequently it is neither present in the SHYS nor in the embryonal liver, only appearing in the foetal stage.

The role of SHYS mesothelium has been assessed as being active in protein transfer (Gulbis et al., 1998; Jauniaux et al., 2000), although others have proposed a merely protective role (Pereda et al., 1999). The only marker that was positive in the mesothelium of the SHYS was D2-40, a monoclonal antibody against podoplanin (Kalof et al., 2009). However, other frequently used mesothelial markers such as calretinin and HBME-1 were negative, although they were not performed in all sacs due to the depletion of tissue in the paraffin blocks.

The above results reveal that the SHYS endodermal cells have a hybrid immunophenotype of both liver and intestinal cells that parallel their synthetic and transport functions. Their predominantly hepatic features of differentiation are present at a histological level (intracytoplasmic vesicles configuring a canalicular system) and immunohistochemically (expression of specific liver cell markers such as AFP, HepPar-1 and GLP3). Moreover, it seems that expression of SALL4 is crucial in liver cell differentiation. The intestinal phenotype is represented by the expression of villin, which is present in both intestine and early liver. Furthermore, CDX2 is characteristic of intestinal cells but absent in liver cells.

\section{Materials and Methods}

26 SHYS were obtained from the routine histopathological archives of our hospital between 1986 and 2007, corresponding to 24 products of conception from spontaneous abortions and 2 tubal ectopic pregnancies. Gestational ages were assessed by taking into account both clinical data and morphological milestones. The earliest sac corresponded to a 5 week tubal pregnancy, 15 were in the $7^{\text {th }}$ to $8^{\text {th }}$ week range and 10 corresponded to the involutive period of 9-11 weeks. All had a good histological preservation, with minor changes of maceration in only 3. Concomitant embryos were found in 11 cases, of these, 8 were fresh and in only 3 were there minor maceration changes.

The SHYS and embryos were formalin fixed and subsequently em- bedded in paraffin and stained with H\&E. Step sections were performed. Immunohistochemistry was done using the antibodies listed in Table 1. Functionally, these antibodies recognize the following functional proteins: $\alpha$-foetoprotein $(A F P)$, a protein is expressed in the early endoderm that binds and transports various ligands, being highly characteristic of yolk sac and immature liver; Glypican 3 (GLP3), a cell surface heparan sulphate proteoglycan is expressed by both yolk sac and liver that acts as a modulator, activating intracellular signaling proteins and growth factors; Hepatocyte-paraffin-1 (HepPar-1), a mitochondrial urea cycle enzyme highly characteristic of embryonal and adult liver cells; Villin, $\mathrm{a} \mathrm{Ca}^{2+}$ regulated actinbinding protein present in both embryonal and adult intestinal cells; CDX2, a protein from a ParaHox gene which interacts in trophoblast differentiation, axial development and particularly, in gut differentiation; $S A L L$, a stem cell nuclear transcriptional factor, expressed in early development as part of a transcriptional core network that maintains the pluripotent properties and self-renewal capacities of embryonal stem cells and Podoplanin (clone $D 2-40$ ), a membrane glycoprotein with mucin-like characteristics that is expressed in the apical membrane of the mesothelium.

Their nuclear, cytoplasmic or membranous expression was analyzed in both the endodermal and mesothelial layers and in the accompanying embryonal tissues when these were available. In some cases, due to the small amounts of tissue, serial sections failed to produce a sufficient number of viable slides for immunohistochemistry. Additionally, in some embryos, the initial haphazard paraffin wax inclusion and block orientation precluded a detailed study of every embryonal organ.

\section{Author's roles}

Francisco F Nogales designed the study and participated in the analysis, execution and manuscript drafting and critical discussion. Isabel Dulcey retrieved archive and clinical material, performed the immunohistochemical and bibliographical analysis and participated in the manuscript drafting and critical discussion.

\section{Acknowledgements}

The authors thank Pablo Goyenaga MD, Hospital de Alajuela, San José, Costa Rica, for his feedback and information about HepPar1. Ovidiu Preda PhD, MasterDiagnostica, Granada, Spain, helped in the design of the illustrations.

\section{References}

BUTLER SL, DONG H, CARDONA D, JIA M, ZHENG R, ZHU H, CRAWFORD JM, LIU C (2008). The antigen for Hep Par 1 antibody is the urea cycle enzyme carbamoyl phosphate synthetase 1. Lab Invest 88: 78-88.

CRAWFORD JM (2002). Development of the intrahepatic biliary tree. Semin Liver Dis 22: $213-226$.

FERRAZZI E, BRAMBATI B, LANZANI A, OLDRINI A, STRIPPARO L, GUERNERI S, MAKOWSKI EL (1988). The yolk sac in early pregnancy failure. Am J Obstet Gynecol 158: 137-142.

FILMUS J, CAPURRO M, RAST J (2008). Glypicans. Genome Biol 9: 224.

GITLIN D, BIASUCCI A (1969). Development of gamma G, gamma A, gamma M, beta IC-beta IA, C 1 esterase inhibitor, ceruloplasmin, transferrin, hemopexin, haptoglobin, fibrinogen, plasminogen, alpha 1-antitrypsin, orosomucoid, betalipoprotein, alpha 2-macroglobulin, and prealbumin in the human conceptus. $J$ Clin Invest 48: 1433-1446.

GITLIN D, PERRICELLI A (1970). Synthesis of serum albumin, prealbumin, alphafoetoprotein, alpha-1-antitrypsin and transferrin by the human yolk sac. Nature 228: 995-997.

GITLIN D, PERRICELLI A, GITLIN GM (1972). Synthesis of -fetoprotein by liver, yolk sac, and gastrointestinal tract of the human conceptus. Cancer Res 32: 979-982.

GULBIS B, JAUNIAUX E, COTTON F, STORDEUR P (1998). Protein and enzyme patterns in the fluid cavities of the first trimester gestational sac: relevance to the absorptive role of secondary yolk sac. Mol Hum Reprod 4: 857-862.

GULBIS B, JAUNIAUX E, DECUYPER J, THIRY P, JURKOVIC D, CAMPBELL S (1994). Distribution of iron and iron-binding proteins in first-trimester human 
pregnancies. Obstet Gynecol 84: 289-293.

GULBIS B, JAUNIAUX E, JURKOVIC D, THIRY P, CAMPBELLS, OOMS HA (1992). Determination of protein pattern in embryonic cavities of human early pregnancies: a means to understand materno-embryonic exchanges. Hum Reprod 7: 886-889.

HESSELDAHL H, LARSEN JF (1969). Ultrastructure of human yolk sac: endoderm, mesenchyme, tubules and mesothelium. Am J Anat 126: 315-335.

HOUGHTON O, CONNOLLY LE, MCCLUGGAGE WG (2008). Morules in endometrioid proliferations of the uterus and ovary consistently express the intestinal transcription factor CDX2. Histopathology 53: 156-165.

HUSTIN J, SCHAAPS JP (1987). Echographic [corrected] and anatomic studies of the maternotrophoblastic border during the first trimester of pregnancy. $A m \mathrm{~J}$ Obstet Gynecol 157: 162-168.

JAUNIAUX E, GULBIS B (2000). Fluid compartments of the embryonic environment. Hum Reprod Update 6: 268-278.

JAUNIAUX E, JOHNS J, BURTON GJ (2005). The role of ultrasound imaging in diagnosing and investigating early pregnancy failure. Ultrasound Obstet Gynecol 25: 613-624.

JAUNIAUX E, JURKOVIC D, HENRIETY, RODESCH F, HUSTIN J (1991). Development of the secondary human yolk sac: correlation of sonographic and anatomical features. Hum Reprod 6: 1160-1166.

JEDRUSIK A, PARFITT DE, GUO G, SKAMAGKI M, GRABAREK JB, JOHNSON MH, ROBSON P, ZERNICKA-GOETZ M (2008). Role of Cdx2 and cell polarity in cell allocation and specification of trophectoderm and inner cell mass in the mouse embryo. Genes Dev 22: 2692-2706.

JONES CJ, JAUNIAUXE (1995a). Ultrastructure of the materno-embryonic interface in the first trimester of pregnancy. Micron 26: 145-173.

JONES CJ, JAUNIAUX E, STODDART RW (1995b). Glycans of the early human yolk sac. Histochem $J$ 27: 210-221.

KALOF AN, COOPER K (2009). D2-40 immunohistochemistry - so far! Adv Anat Pathol 16: 62-64.

KANDIL D, LEIMAN G, ALLEGRETTA M, TROTMAN W, PANTANOWITZ L, GOULART R, EVANS M (2007). Glypican-3 immunocytochemistry in liver fine-needle aspirates: a novel stain to assist in the differentiation of benign and malignant liver lesions. Cancer 111: 316-322.

KHURANAS, GEORGE SP (2008). Regulation of cell structure and function by actinbinding proteins: villin's perspective. FEBS Lett 582: 2128-2139.

KUCUKT, DURUNK, YENEN MC, DEDE M, ERGUNA, BASERI (1999). Yolk sac size and shape as predictors of poor pregnancy outcome. J Perinat Med 27: 316-320.

LUGLIA, TORNILLO L, MIRLACHER M, BUNDI M, SAUTER G, TERRACCIANO LM (2004). Hepatocyte paraffin 1 expression in human normal and neoplastic tissues: tissue microarray analysis on 3,940 tissue samples. Am J Clin Pathol122: 721-727.

MAUNOURY R, ROBINE S, PRINGAULT E, HUET C, GUENET JL, GAILLARD JA, LOUVARD D (1988). Villin expression in the visceral endoderm and in the gut anlage during early mouse embryogenesis. EMBO J 7: 3321-3329.

MIZEJEWSKI GJ (2001). Alpha-fetoprotein structure and function: relevance to isoforms, epitopes, and conformational variants. Exp Biol Med (Maywood) 226: 377-408.

MOSKALUK CA, ZHANG H, POWELL SM, CERILLI LA, HAMPTON GM, FRIERSON HF, Jr. (2003). Cdx2 protein expression in normal and malignant human tissues: an immunohistochemical survey using tissue microarrays. Mod Pathol 16: 913-919.
NICOLAE A, GOYENAGA P, MCCLUGGAGE WG, PREDA O, NOGALES FF (2011) Endometrial intestinal metaplasia: a report of two cases, including one associated with cervical intestinal and pyloric metaplasia. Int J Gynecol Pathol 30: 492-496.

NOGALES-FERNANDEZ F, SILVERBERG SG, BLOUSTEIN PA, MARTINEZHERNANDEZ A, PIERCE GB (1977). Yolk sac carcinoma (endodermal sinus tumor): ultrastructure and histogenesis of gonadal and extragonadal tumors in comparison with normal human yolk sac. Cancer 39: 1462-1474.

NOGALES, F. BELTRAN, E. and FERNÁNDEZ, P.L. (1992). The Pathology of Secondary Human Yolk Sac in spontaneous abortion: Findings in 103 cases. In Progress in Surgical Pathology (eds. C. Fenoglio, M. Wolf and F. Rilke). Field \& Wood, Philadelphia, pp. 291-303.

NOGALES, F. BELTRAN, E. and GONZALEZ, F. (1993). Morphological Changes of the Secondary Human Yolk Sac in Early Pregnancy Wastage. In The Human Yolk Sac and Yolk Sac Tumours (ed. F.F. Nogales). Springer-Verlag; Berlin pp. 174-194.

NOGALES, F.F. (1995). The Pathology of Human Yolk Sac In Haines and Taylor's Obstetrical and Gynaecological Pathology (eds. H. Fo and M. Wells). Churchill Livingstone; London. pp. 1677-1688.

NOGALES FF, PREDA O, NICOLAE A (2012). Yolk sac tumours revisited. A review of their many faces and names. Histopathology 60: 1023-1033.

OIKAWA T, KAMIYA A, KAKINUMA S, ZENIYA M, NISHINAKAMURA R, TAJIRI H, NAKAUCHI H (2009). Sall4 regulates cell fate decision in fetal hepatic stem/ progenitor cells. Gastroenterology 136: 1000-1011.

PEREDAJ, MOTTAPM (1999). New advances in human embryology: morphofunctional relationship between the embryo and the yolksac. Med Electron Microsc. 32:67-78.

PREDAO, NICOLAEA, ANEIROS-FERNANDEZ J, BORDAA, NOGALES FF (2011). Glypican 3 is a sensitive, but not a specific, marker for the diagnosis of yolk sac tumours. Histopathology 58: 312-314; author reply 314-315.

ROBINES, HUETC, MOLLR, SAHUQUILLO-MERINO C, COUDRIERE, ZWEIBAUM A, LOUVARD D (1985). Can villin be used to identify malignant and undifferentiated normal digestive epithelial cells? Proc Natl Acad Sci USA 82: 8488-8492.

SCHMIDT P, HORMANSDORFER C, BOSSELMANN S, ELSASSER M, SCHARF A (2011). Is the yolk sac a new marker for chromosomal abnormalities in early pregnancy? Arch Gynecol Obstet 283 Suppl 1: 23-26.

SHI WK, HOPKINS B, THOMPSON S, HEATH JK, LUKE BM, GRAHAM CF (1985), Synthesis of apolipoproteins, alphafoetoprotein, albumin, and transferrin by the human foetal yolk sack and other foetal organs. J Embryol Exp Morpho/85: 191-206.

STRINGER EJ, DULUC I, SAANDIT, DAVIDSON I, BIALECKA M, SATO T, BARKER N, CLEVERS H, PRITCHARD CA, WINTON DJ, WRIGHT NA, FREUND JN, DESCHAMPS J, BECK F (2012). Cdx2 determines the fate of postnatal intestinal endoderm. Development 139: 465-474.

TAKASHINA T. (1993). Histology of the Secondary Human Yolk Sac with Special Reference to Hematopoesis. In The Human Yolk Sac and Yolk Sac Tumours (ed. F.F. Nogales). Springer-Verlag; Berlin,

WENNERBERG AE, NALESNIK MA, COLEMAN WB (1993). Hepatocyte paraffin 1:a monoclonal antibody that reacts with hepatocytes and can be used for differential diagnosis of hepatic tumors. Am J Pathol 143: 1050-1054.

ZHANG J, TAM WL, TONG GQ, WU Q, CHAN HY, SOH BS, LOU Y, YANG J, MA Y, CHAI L, NG HH, LUFKINT, ROBSON P, LIM B (2006). Sall4 modulates embryonic stem cell pluripotency and early embryonic development by the transcriptional regulation of Pou5f1. Nat Cell Biol 8: 1114-1123. 


\section{Further Related Reading, published previously in the Int. J. Dev. Biol.}

Primitive and definitive erythropoiesis in the yolk sac: a bird's eye view Guojun Sheng

Int. J. Dev. Biol. (2010) 54: 1033-1043

The origin and fate of yolk sac hematopoiesis: application of chimera analyses to developmental studies Hiroo Ueno and Irving L. Weissman

Int. J. Dev. Biol. (2010) 54: 1019-1031

Novel methods for determining hematopoietic stem and progenitor cell emergence in the murine yolk sac Christopher T. Lux and Mervin C. Yoder

Int. J. Dev. Biol. (2010) 54: 1003-1009

C/EBPalpha and C/EBPbeta are markers of early liver development

Adam Westmacott, Zoë D. Burke, Guillermo Oliver, Jonathan M.W. Slack and David Tosh Int. J. Dev. Biol. (2006) 50: 653-657

Differentiation of human embryonic stem cells into hepatocytes in 2D and 3D culture systems in vitro Hossein Baharvand, Seyed M. Hashemi, Saeid Kazemi Ashtiani and Ali Farrokhi Int. J. Dev. Biol. (2006) 50: 645-652

Quantitative gene expression profiling reveals a fetal hepatic phenotype of murine ES-derived hepatocytes Andrea Jochheim, Tina Hillemann, Gabriela Kania, Jennifer Scharf, Masoumeh Attaran, Michael P Manns, Anna M Wobus and Michael Ott Int. J. Dev. Biol. (2004) 48: 23-29

Multilineage hematopoietic progenitor activity generated autonomously in the mouse yolk sac: analysis using angiogenesis-defective embryos

Christine Rampon and Philippe Huber

Int. J. Dev. Biol. (2003) 47: 273-280

Targeted disruption of fibroblast growth factor receptor-1 blocks maturation of visceral endoderm and cavitation in mouse embryoid bodies Milan Esner, Jiri Pachernik, Ales Hampl and Petr Dvorak Int. J. Dev. Biol. (2002) 46: 817-825

Production of alpha-fetoprotein by human submandibular gland T Tsuji and N Nagai

Int. J. Dev. Biol. (1993) 37: 497-498

Visceral yolk sac-derived tumors H Sobis, A Verstuyf and M Vandeputte Int. J. Dev. Biol. (1993) 37: 155-168

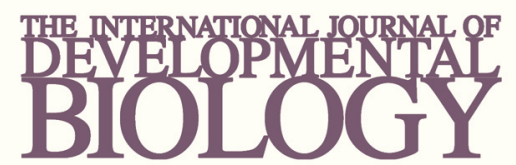

Volume 54 Nos. 6/7

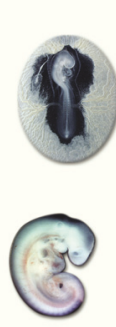

Special Issue

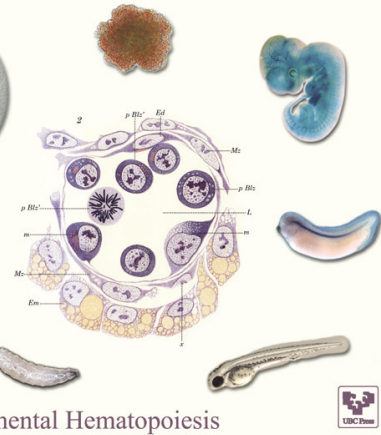

5 yr ISI Impact Factor $(2011)=2.959$

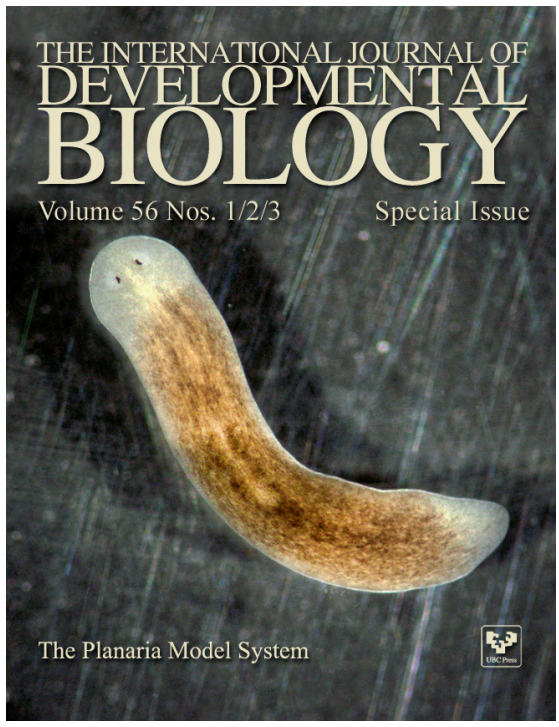

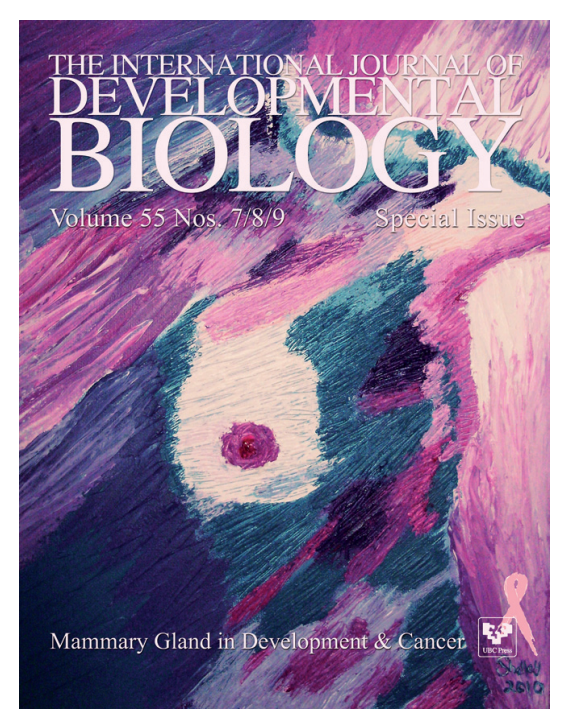

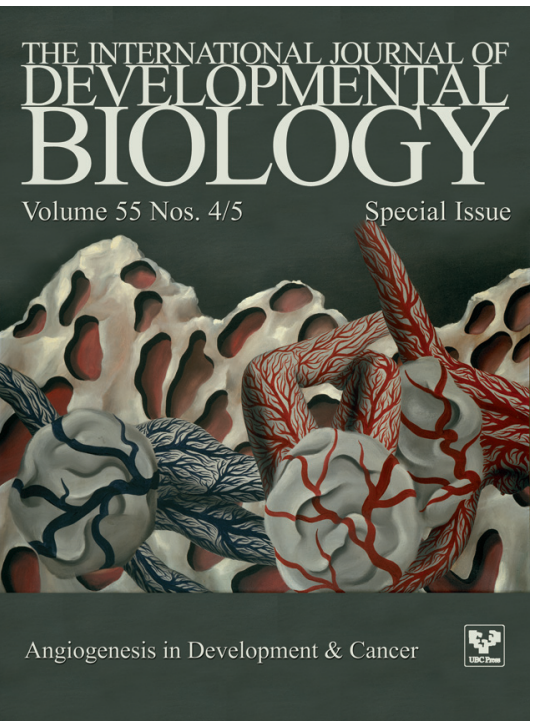

